\title{
Effect of Consultation and Educating in Preparation Classes for Delivery on Pregnancy Consequences: A Randomized Controlled Clinical Trial
}

\author{
Simin Karimi ${ }^{1}$, Farideh Kazemi ${ }^{2}$, Seyedeh Zahra Masoumi ${ }^{3}$, Fatemeh Shobeiri ${ }^{3}$, Ghodratollah Roshanaei ${ }^{4}$
}

${ }^{1}$ M.Sc. of Consultation in Midwifery, Department of Midwifery, School of Nursing and Midwifery, Hamadan University of Medical Sciences, Hamadan, Iran

${ }^{2}$ Ph.D. Candidate of Reproductive Health, Department of Midwifery \& Reproductive Health, School of Nursing \& Midwifery, Shahid Beheshti University of Medical Sciences, Tehran, Iran

${ }^{3}$ Mother \& Child Care Research Center, School of Nursing and Midwifery, Hamadan University of Medical Sciences, Hamadan, Iran

${ }^{4}$ Ph.D. of Biostatistics, Associate Professor, Department of Biostatistics and Epidemiology, School of Health, Hamadan University of Medical Sciences, Hamadan, Iran

\section{Type of article: Original}

\begin{abstract}
Background: Care during pregnancy and performing consultation for delivery preparation play an important role in improving pregnant women's knowledge.

Objective: The purpose of this study was to investigate the effect of consultation and instruction in the preparation classes for delivery on pregnancy consequences, including choosing the type of delivery, the performed type of delivery, and infant's weight.

Methods: This study was conducted in 2015 on 170 pregnant women who had been referred to the prenatal clinic in Hamedan. The participants were randomly divided into intervention and control groups. Eight sessions of consultation for delivery preparation were held for the women in 20 to 36 weeks of pregnancy. The control group received only the routine care. After 37 weeks of pregnancy, the participants answered a questionnaire. The infant's weight was measured after birth. Data were analyzed Using SPSS-21 and McNemar-Bowker Test, independent t-test, chi-square test, and Fisher exact test.

Results: Results showed a significant statistical difference between the two groups concerning their selective and performed delivery $(p<0.001)$. The weight of infants in the intervention group was significantly higher than that of those in the control group $(\mathrm{p}<0.001)$.

Conclusion: The findings of this study showed that the consultation for delivery preparation had a positive effect on some pregnancy consequences such as selecting the type of delivery performed and infant's weight.

Trial registration: The trial was registered at the Iranian Registry of Clinical Trials (http://www.irct.ir) with the IRCTID: IRCT2015012513405N9.

Funding: The authors received no financial support for the research, authorship, and/or publication of this article.

Keywords: Caesarean section, Delivery, Consulting, Education
\end{abstract}

\section{Introduction}

Although medical progress has increased the immunity of delivery, simultaneously different types of intervention in delivery have been so developed that the concept of delivery as a physiological phenomenon has been lost (1). Over the recent years all over the world, including in Iran, caesarean has become an increasingly popular process. For example, in the United States, caesarean delivery has progressed from $4.5 \%$ in 1965 to $38 \%$ in 2007 (2-5). Based on DHS in 2000, the rate of caesarean in Iran has been 35\%; based on IMES in 2005, it has been $40.4 \%$; and based on MIDHS in 2010, the last statistics in Iran, it has been $45.55 \%$ of all type of delivery (6). The method of delivery can

\section{Corresponding author:}

Assistant Professor Dr. Seyedeh Zahra Masoumi, Research Center for Child \& Maternity Care, School of Nursing and Midwifery, Hamadan University of Medical Sciences, Hamadan, Iran. Tel: +98.9183129058, Fax: +98.8138380447, Email: zahramid2001@yahoo.com

Received: July 04, 2016, Accepted: September 17, 2016, Published: November 2016

iThenticate screening: August 08, 2016, English editing: October 12, 2016, Quality control: October 27, 2017

(C) 2016 The Authors. This is an open access article under the terms of the Creative Commons Attribution-NonCommercialNoDerivs License, which permits use and distribution in any medium, provided the original work is properly cited, the use is non-commercial and no modifications or adaptations are made. 
positively affect the mother and infant's health (7). Generally, the medical-intervention abuse in the process of natural delivery leads to caesarean statistical increase and, consequently, to the increase of its side effect. During the last 30 years, caesarean has not improved the results of pregnancy and delivery. The purpose of caesarean was primarily to save the mother's life in the case of problematic deliveries. Its use, however, has increased during years (8). During the recent decade, the increasing rate of caesarean and the changes in the reasons for its use has become a serious problem concerning mother and infants' health and as an extra economic load upon the health and medication systems of the country (9). Nowadays, in most advanced countries of the world, adapting new policies about mother and infant's health and doing interventions, attempts have been made to reduce the caesarean rate. The high statistics and figures of caesarean in the country and our distance from the World Health Organization (doing caesarean to the extent of $15 \%$ until 2010) have made researchers and authorities of women public health so worried that, in Iran and other countries simultaneously, a lot of attempts have been in regards to physiological delivery classes during pregnancy and physiological delivery. The principles of physiological delivery have been developed based on the evidence of the World Health Organization (10). The principle of physiological management has been preventive and supportive, hence causing caesarean to be reduced to the extent of $4 \%$ and the mortality of mother and infant to be the least $(11,12)$. According to the Office of the Ministry Of Health, maternal factors are involved in the caesarean increase in Iran. Factors include fear of pain and intolerable anxiety of natural delivery (13). Using modern delivery methods such as nonmedical and supportive treatments (14), which are taught in consultation classes, we can change delivery to a pleasant occurrence for the mothers via improving the psychological and emotional aspects of delivery; reducing the severity of pain and fear, we can decrease tendency toward caesarean. Hence, delivery-preparation counseling meetings have been suggested to primarily be held comprehensively in all clinics and hospitals to teach the performance of physiological delivery to all midwives and pregnant mothers, which will be an effective step toward the improvement of the delivery process in the country via elevating the medical staffs' knowledge, believing in the suitability of the method, and creating the spirit of self-believing in pregnant mothers to deliver naturally (15). Care during pregnancy and delivery-preparation consultation, which are an important duty in midwifery, may be effective in increasing a pregnant woman's knowledge. Midwives may provide the pregnant women with valuable pieces of information during their pregnancy through consultation. Because the educational scope of delivery-preparation classes, including nutrition and physical activities, affect the pregnancy consequences, we may correct incorrect health behaviors, improve the pregnancy consequences, and change the pregnancy period and delivery to a pleasant memory through midwifery education and consultation based on GATHER principles (establishing relationship, interaction, presenting useful and suitable pieces of information, explaining various pregnancy and delivery issues, following the mothers up in counseling and educational meetings). Because providing pregnant women with education and consultation before, during, and after delivery is considered as the crucial duty of the midwives, the educational and counseling role of the midwives is important and undeniable and can affect the performance of the pregnant woman. Therefore, this study has dealt with the effect of consultation and education in the classes for delivery preparation on the delivery consequences, including the selection of the type of delivery, the type of delivery performed, and the infant's weight.

\section{Material and Methods}

\subsection{Trial design and participants}

This study was included a randomized clinical trial, which was conducted in January 2015 to June 2015. This study was performed on the pregnant women who, regarding pregnancy care, had been referred to the prenatal clinic of Fatemieh Hospital, Hamadan, Iran. Based on information from the article performed by Jamilian et al. (16) and considering $\alpha=0.05$ and power $=90 \%$ and accounting for $10 \%$ loss in the samples, 85 participants were calculated for each group.

\subsection{Selection criteria}

The inclusion criteria were including mono-fetus pregnancy, gestational age of 20-23 weeks, not experiencing repeated abortion, not experiencing caesarean in multi-pa patients, not having taken part in similar educational classes, having normal BMI, not being affected with the side effect of pregnancy period such as placenta previa, preeclampsia, diabetes mellitus, and not being affected with chronic diseases such as diabetes, cardiovascular diseases, and epilepsy. Absence in more than one session of counseling was exclusion criterion.

\subsection{Interventions}

Prenatal care files of pregnant women were studied, after receiving a written introduced from the Hamedan University of Medical Sciences and an introduction letter of the ethics committee and permission from the clinic, and selected women were the criteria for inclusion. Instruments used to collect the data were demographic questionnaires and the balance of weighing the infant. The researcher-made demographic questionnaire consisted of 
26 items in regards to demographic and midwifery information of participants during their previous and current pregnancy. Ten faculty member validated the questionnaire. The validity of the weighing balance also was confirmed by its manufacturer and standard trade mark. To be exact in every measurement, a standard weight was used, and the balance was calibrated at the beginning and after 10 times of weighing. Before any educational meeting, some items of the demographic questionnaire were administered to the groups as a pretest in the form of interviewing. Then, the intervention group was exposed to eight sessions of delivery preparation. The educational program or syllabus covered anatomy and physiology of the patient's genital organs, personal health, nutrition, warning signs, and mental health during and after pregnancy and delivery. It also included the explanation of advantages and disadvantages of types of delivery and painlessness, issues related to after delivery, infant and breast feeding, teaching breathing exercises, massage, and exercises during pregnancy via face-to-face group teaching, educational $\mathrm{CD}$, practical teaching of exercises, and booklets. In each class, mostly 10 mothers took part. The educational materials were taught theoretically and practically to the mothers in 90 minutes by a well-educated midwife, who holds a certificate in physiological delivery performance based on the principles of GATHER consultation. The control group received only the pregnancy routine care. Finally, the questionnaire was administered to the two groups at the end of 37 weeks of pregnancy. The infant's weight was measured after birth. To this end, digital balance was used, and before each measuring its correctness was tested using a weight of $1 \mathrm{~kg}$.

\subsection{Outcomes}

The primary outcomes were type of preferred delivery, type of performed delivery, and infant's weight.

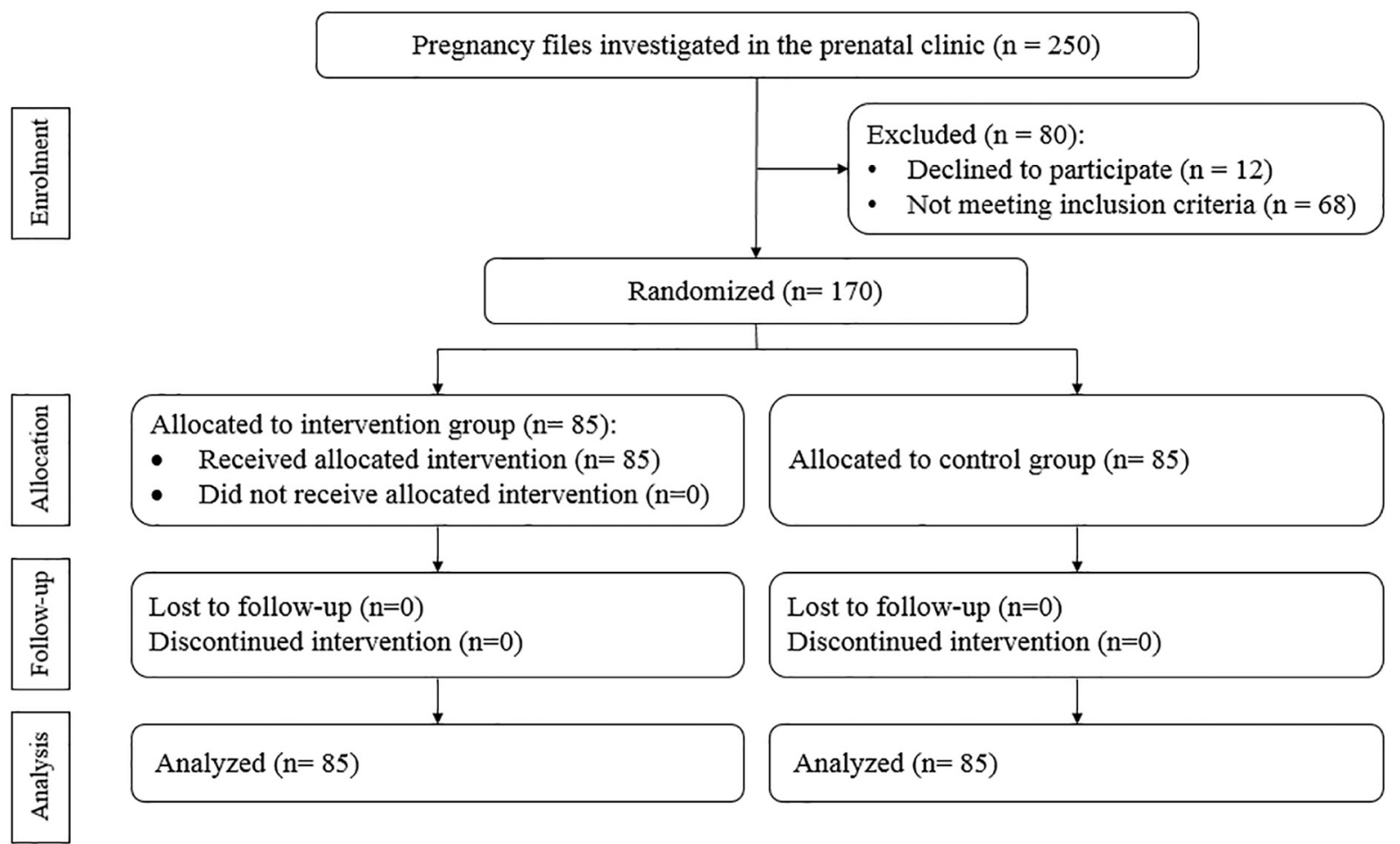

Figure 1. Flow diagram of the participants

\subsection{Randomization and blinding}

Before the study, the allocation sequence was determined by one of the members of the research team not involved in the samples selection using four randomized blocking and tables of the computer random numbers; the participants were located randomly, with a ratio of 1:1 in the intervention and control groups. The codes related to each participant were located in opaque envelopes for hiding the allocation. Thus, the subjects were in A and B groups according to the specified sequence (Figure 1). Due to the type of performed intervention, it was not possible to blind the participants and the educator, but the data analyzer was not aware of the interventions provided to the groups. 


\subsection{Statistical methods}

Using SPSS, version 21, the data were analyzed. To check the normality of the data, a Kolmogorov-Smirnov test was run. To describe the participants' personal characteristics, descriptive statistics (number, percentage, mean, and standard deviation) were used. The inferential statistics run to test the hypotheses were McNemar-Bowker test, independent t-test, chi-square, and Fisher exact test. The significant criterion was considered to be $p<0.05$.

\subsection{Research ethics}

Before starting the study, 170 pregnant women were informed about its objectives and were selected to participate after obtaining written consent. We also observed all ethical issues in accordance with the last version of the Declaration of Helsinki. The Ethics Committee of Research Deputy of Hamedan University of Medical Sciences approved the study with the number P/6371/9/35/16 on March 2, 2015. This study also was registered in the Iranian Registry of Clinical Trials (irct.ir) with the ID: IRCT2015012513405N9. We were committed to keeping all of the participants' information confidential. It should be noted that this study did not interfere in the process of routine care of participants.

\section{Results}

Table 1 shows that the age of $71.8 \%$ of the women in the intervention group and $60 \%$ in the control group ranged from 20 to 30 years old. The majority of the women in the both groups had received a high school diploma. More than $90 \%$ of the pregnant women in the two groups were housewives. The majority of participants in both groups belonged to the families whose monthly income was lower than 10 million Rials. The findings also showed that most of the women in the both groups had not previously experienced pregnancy. Before performing the act of consultation, the favorite delivery method was compared between the groups, and the result showed no significant difference $(p=0.11)$ between them. However, after consultation classes, a significant difference $(p<0.001)$ was observed between the two groups as far as the selection of delivery method was concerned. The result also showed a significance difference $(\mathrm{p}<0.001)$ between selective methods of delivery before and after consultation as to the intervention group. This, however, was not the case concerning the control group $(\mathrm{p}=0.15)$ (Table 2). After educational classes and after delivery, the women in the two groups were compared as far as the performed delivery was concerned. The result showed a significant difference $(p<0.001)$. There was also a significant difference $(p=0.002)$ between the neonatal weight means in the two groups; that is, the weight of those who belonged to the intervention group was higher than that of those in the control group (Table 3).

Table 1. Demographic characteristics of participants, by groups

\begin{tabular}{|c|c|c|c|c|}
\hline \multicolumn{2}{|l|}{ Variables } & $\begin{array}{l}\text { Intervention group; } n= \\
85\end{array}$ & $\begin{array}{l}\text { Control group; } n= \\
85\end{array}$ & $\begin{array}{l}\mathrm{p}- \\
\text { value }\end{array}$ \\
\hline \multirow[t]{4}{*}{ Age (year) } & $<20$ & $6(7.0)$ & $12(14.1)$ & \multirow[t]{4}{*}{0.21} \\
\hline & $20-30$ & $61(71.8)$ & $51(60.0)$ & \\
\hline & $31-40$ & $18(21.2)$ & $21(24.7)$ & \\
\hline & $>40$ & $0(0.0)$ & $1(1.2)$ & \\
\hline \multirow[t]{4}{*}{ Education level } & Elementary & $12(14.1)$ & $20(23.5)$ & \multirow{4}{*}{$0.19^{*}$} \\
\hline & Middle & $15(17.6)$ & $18(21.2)$ & \\
\hline & $\begin{array}{l}\text { High school } \\
\text { diploma }\end{array}$ & $31(36.5)$ & $25(29.4)$ & \\
\hline & Academic & $27(31.8)$ & $22(25.9)$ & \\
\hline \multirow[t]{2}{*}{ Occupation } & Housewife & $78(91.8)$ & $82(96.5)$ & \multirow[t]{2}{*}{0.33} \\
\hline & Employed & $7(8.2)$ & $3(3.5)$ & \\
\hline \multirow[t]{4}{*}{ Household Income } & $<10$ Million Rials & $50(58.8)$ & $63(74.1)$ & \multirow[t]{4}{*}{0.06} \\
\hline & 10-20 Million Rials & $33(38.8)$ & $22(25.9)$ & \\
\hline & 20-30 Million Rials & $1(1.2)$ & $0(0.0)$ & \\
\hline & $>40$ Million Rials & $1(1.2)$ & $0(0.0)$ & \\
\hline \multirow{5}{*}{$\begin{array}{l}\text { Number of previous } \\
\text { pregnancy }\end{array}$} & 0 & $48(56.5)$ & $37(43.5)$ & \multirow[t]{5}{*}{0.09} \\
\hline & 1 & $26(30.6)$ & $30(35.3)$ & \\
\hline & 2 & $8(9.4)$ & $11(12.9)$ & \\
\hline & 3 & $3(3.5)$ & $5(5.9)$ & \\
\hline & 4 & $0(0.0)$ & $2(2.4)$ & \\
\hline
\end{tabular}

*Chi-square test, the rest Fisher's exact test 
Table 2. Comparing the intervention and control groups in terms of desired delivery method

\begin{tabular}{|l|l|l|l|l|l|l|l|}
\hline \multirow{2}{*}{$\begin{array}{l}\text { Desired } \\
\text { delivery } \\
\text { method }\end{array}$} & \begin{tabular}{l} 
Intervention group; $n(\%)$ \\
\cline { 2 - 7 } \\
vormal \\
velivery
\end{tabular} & $\begin{array}{l}\text { Physiologic } \\
\text { delivery }\end{array}$ & $\begin{array}{l}\text { Cesarean } \\
\text { section }\end{array}$ & $\begin{array}{l}\text { Control group; } n(\%) \\
\text { Normal } \\
\text { vaginal } \\
\text { delivery }\end{array}$ & $\begin{array}{l}\text { Physiologic } \\
\text { delivery }\end{array}$ & $\begin{array}{l}\text { Cesarean } \\
\text { section }\end{array}$ & value \\
\hline $\begin{array}{l}\text { Before } \\
\text { intervention }\end{array}$ & $54(63.5)$ & $5(5.9)$ & $26(30.6)$ & $45(52.9)$ & $2(2.4)$ & $38(44.7)$ & 0.11 \\
\hline $\begin{array}{l}\text { After } \\
\text { intervention }\end{array}$ & $5(5.9)$ & $79(92.9)$ & $1(1.2)$ & $43(50.6)$ & $4(4.7)$ & $38(44.7)$ & $<0.001$ \\
\hline p-value & $<0.001$ & & & 0.15 & & & \\
\hline
\end{tabular}

Table 3. Comparing the intervention and control groups in terms of type of delivery and neonatal weight in birth

\begin{tabular}{|l|l|l|l|}
\hline Type of delivery & Intervention group & Control group & p-value \\
\hline Normal vaginal delivery & $13(15.3)$ & $26(36.0)$ & $<0.001$ \\
\hline Physiologic delivery & $46(54.1)$ & $0(0.0)$ & \\
\hline Elective cesarean section & $1(1.2)$ & $16(18.8)$ & \\
\cline { 1 - 3 } Emergency cesarean section & $25(29.4)$ & $43(56.0)$ & \\
\hline Neonatal weight in birth, gr & $3224.47 \pm 390.83$ & $2994.71 \pm 540.20$ & 0.002 \\
\hline
\end{tabular}

\section{Discussion}

The present study investigated the effect of consultation and education through classes for delivery preparation on choosing delivery method, type of performed delivery, and the newborn's weight. The result showed that consultation during pregnancy can positively affect the three above-mentioned dependent variables. In this study, after the treatment, women's tendency toward caesarean declined. The results of Tofighi Niaki et al. (17) also showed that receiving education while pregnant reduced women's interest in caesarean to half. The results of this study showed that about $80 \%$ of the participants preferred natural delivery after receiving education; finally, $57.6 \%$ of them experienced natural delivery. Although only $1.2 \%$ of the participants under study had chosen caesarean, the follow-up, after delivery, revealed that $30 \%$ of patients in the intervention group had tolerated emergency caesarean. Thus, it can be stated that the high number of caesarean in the country is due to the factors, other than the mother's choice, such as unnecessary interventions in the process of delivery. The result of this study is similar to that of Arefi et al. (18). The authors showed that receiving education could reduce the rate of caesarean in the intervention group significantly. Fear of delivery is one of the factors that leads to caesarean. This is verified by the study conducted by Storksen et al. (19). The results of their study showed that $80 \%$ of their participants were afraid of delivery, and, although this fear was related to elective caesarean and caesarean section, the majority of their participants did not go under caesarean operation. The main predictive variables were actually elective caesarean, risky medical factors, and negative experience of the previous delivery. However, via modern methods of delivery such as nonmedical and supporting treatments, which are taught in the meetings of consultation for delivery preparation, we can change delivery into a pleasant and enjoyable occurrence for the mother through the improvement of psychological and emotional aspects of delivery, and, through reducing the severity of pain and fear, we may decrease elective caesarean (15). Another finding of the present study was the higher weight of the infants whose mother were in the intervention group. This may be attributed to the effect of correct nutrition taught to the mothers in the group. Pregnancy is a special period of life when nutrition needs increase $(20,21)$. To enjoy the natural pregnancy period and its pleasant consequences, the mother should receive adequate nutrient-laden foods (20). Imbalance in diet may bring negative consequences to both mothers and their infants for a long time (21). Because pregnancy provides women with a suitable opportunity for education, we should elevate the knowledge of society concerning desirable nutrition behaviors in various period of time such as that of pregnancy (22). Unfortunately, those in service in health and prenatal centers do not consume time in which to educate pregnant women, hence leading to unsuitable nutrition among pregnant women. Mirmolaei et al. (22) showed that teachings and classes held for women during their pregnancy can positively affect nutrition behaviors. Garg and Kashyap (23) found that consultation and nutrition teaching improves the pregnant mother's nutrition status. Shakeri et al. (24) came to the conclusion that the majority of pregnant mothers had suitable nutrition behaviors after taking part in educational classes, and there was a significant difference between the mean score of the intervention group and that of the control. Mourin et al.'s (25) study also showed that the effect of education on nutrition behavior was significant. Vakita and Myosh (26) concluded that nutrition education during pregnancy can significantly cause the 
mothers to receive some food groups (received energy and proteins). In many previous studies $(27,28)$, to avoid ethical misunderstanding, the mothers were allowed to be a member of the groups voluntarily. This had threatened the validity of the data. One of the strengths of this study, however, was randomization. That is, after receiving the mothers' conscious consent to take part in the study, they were randomly assigned to groups. This study had its own limitations. It was rather longitudinal and time consuming (from the 20th week of pregnancy to after the delivery), which made it difficult to access the participants. The research project required many sessions of teaching. Because the mothers were not on time as far as their participation in the teaching classes was concerned, the researcher had to hold makeup classes for 10 mothers.

\section{Conclusions}

The findings of this study indicate that consultation for delivery preparation positively affects some pregnancy consequences such as choosing the type of delivery, the type of delivery performed, and the infant's weight. Hence, more classes for delivery preparation are suggested to be held in pregnancy care centers in order to adapt the mothers to different steps of delivery in a better way, decrease mothers' tendency toward elective caesarean, and, finally, encourage the other pregnant mothers to prefer natural and/or physiological delivery.

\section{Acknowledgments:}

This study was supported by the research deputy of the Hamedan University of Medical Sciences. The authors would like to acknowledge the research deputy and the ethics committee of the university and the entire participant and the authorities and staff in the Fatemieh Hospital of Hamedan for their cooperation.

\section{Trial registration:}

The trial was registered at the Iranian Registry of Clinical Trials (http://www.irct.ir) with the IRCTID: IRCT2015012513405N9.

\section{Funding:}

The authors received no financial support for the research, authorship, and/or publication of this article.

\section{Conflict of Interest:}

There is no conflict of interest to be declared.

\section{Authors' contributions:}

All authors contributed to this project and article equally. All authors read and approved the final manuscript.

\section{References:}

1) Lowe NK. Self-efficacy for labor and childbirth fears in nulliparous pregnant women. J Psychosom Obstet Gynaecol. 2000; 21(4): 219-24. doi: 10.3109/01674820009085591. PMID: 11191169.

2) Cunningham G, Leveno JK, Bloom SL, Hauth JC, Rouse DJ, Spong CY. Williams Obstetrics. 24 ed. New York: McGraw-Hill. 2014; 177.

3) Bragg F, Cromwell D, Edozien L, Gurol-Urganci I, Mahmood T, Templeton A, et al. Variation in Rates of Cesarean Section Among English NHS Trusts After Accounting for Maternal and Clinical Risk: Crosssectional Study. Obstetric Anesthesia Digest. 2011; 31(3): 160-1. doi: 10.1136/bmj.c5065.

4) Phadungkiatwattana $P$, Tongsakul N. Analyzing the impact of private service on the cesarean section rate in public hospital Thailand. Arch Gynecol Obstet. 2011; 284(6): 1375-9. doi: 10.1007/s00404-011-1867-0. PMID: 21359844.

5) Tillett J. Should elective cesarean birth be an accepted option for women? J Perinat Neonatal Nurs. 2005; 19(1): 4-6. doi: 10.1097/00005237-200501000-00003. PMID: 15796417.

6) Rashidian A. Health Observatory: First Report I.R. Iran Multiple-Indicator Demographic and Health Survey 2010. Tehran: Ministry of health, medicine, and medical education, medicine deputy. 2011.

7) Shakeri M, Mazloumzade S, Mohamaian F. Factors affecting the rate of cesarean section in Zanjan maternity hospitals in 2008. The Scientific Journal of Zanjan University of Medical Sciences. 2012; 20(80): 98-104.

8) Danforth DN, Gibbs RS. Danforth's obstetrics and gynecology: Lippincott Williams \& Wilkins. 2008.

9) Sagiry M, Satar zadeh N, Tabrizy N, Pezeshky Z. Comparison severity pain with use entonox and outcome neonatal in primary gravity. Journal of Ardabil University of Medical Sciences. 2008; 1(8): 62-7. 
10) American College of Obstetricians and Gynecologists. ACOG practice bulletin: Intrapartum fetal heart rate monitoring. Obstet Gynecol. 2005; 106(2): 1453-6.

11) Enkin M, Keirse MJ, Chalmers I, Enkin E. A guide to effective care in pregnancy and childbirth: Oxford university press Oxford. 2000.

12) Sagady M, Gordon H. The Cesarean Section Program, Outcome Management Associates. Births. 1998: $109-21$.

13) Goodman P, Mackey MC, Tavakoli AS. Factors related to childbirth satisfaction. J Adv Nurs. 2004; 46(2): 212-9. doi: 10.1111/j.1365-2648.2003.02981.x. PMID: 15056335.

14) Bolbol-Haghighi N, Masoumi SZ, Kazemi F. Effect of Massage Therapy on Duration of Labour: A Randomized Controlled Trial. Journal of clinical and diagnostic research: JCDR. 2016; 10(4): 12-5. doi: $10.7860 / \mathrm{jcdr} / 2016 / 17447.7688$.

15) Sehhati Shafai F, Kazemi S, Ghojazadeh M. Comparing maternal outcomes in nulliparous women in labor in physiological and conventional labor: a randomized clinical trial. J Mazandaran Univ Med Sci. 2013; 22(97): 122-31.

16) Jamilian M, Mobasseri SH, Wakilian K, Jamilinan H.R. Effect of Childbirth Preparation Classes on The Duration of Admission and Satisfaction of Mothers. Scientific Journal of Ilam University of Medical Sciences. 2013; 21(2): 44-50.

17) Tofighi Niaki M, Behmanesh F, Mashmuli F, Azimi H. The effect of prenatal group education on knowledge, attitude and selection of delivery type in primiparous women. Iranian Journal of Medical Education. 2010; 10(2): 124-30.

18) Arefi Z, Hekamatpou D, Orouji MA, Shaahmadi Z, Khushemehri G, Shaahmadi F. The Effect of Educational Intervention based on BASNEF Model on Decreasing the Cesarean Section Rate among Pregnant Women in Khomain Country. J Family Reprod Health. 2015; 9(3): 101-5. PMID: 26622307, PMCID: PMC4662752.

19) Størksen HT, Garthus-Niegel S, Adams SS, Vangen S, Eberhard-Gran M. Fear of childbirth and elective caesarean section: a population-based study. BMC Pregnancy Childbirth. 2015; 15: 221. doi: 10.1186/s12884-015-0655-4. PMID: 26382746, PMCID: PMC4573308.

20) Verbeke W, De Bourdeaudhuij I. Dietary behaviour of pregnant versus non-pregnant women. Appetite. 2007; 48(1): 78-86. doi: 10.1016/j.appet.2006.07.078. PMID: 17005297.

21) Mohammad Alizadeh Charandabi S, Kamali Fard M, Ebrahimi Mamqani M, Asghari Jafarabadi M, Omidi F. Evaluation of the nutritional behavior of women in first trimester of pregnancy and its relationship with some socio-demographic characteristics of whom referred to health centers in Karaj. Iranian Journal of Obstetrics, Gynecology and Infertility. 2012; 15(18): 10-8.

22) Mirmolaei T, Moshrefi M, Kazemnejad A, Farivar F, Morteza H. Effects of feeding behavior of pregnant women. Faculty of Nursing and Midwifery's Journal of Tehran University of Medical Sciences. 2009; 15(4): $35-42$.

23) Garg A, Kashyap S. Effect of counseling on nutritional status during pregnancy. Indian J Pediatr. 2006; 73(8): 687-92. doi: 10.1007/BF02898446. PMID: 16936363.

24) Shakeri M, Mazlomzade S, Mohamaian F, Bateni J. Effectiveness of Antenatal Preparation for Childbirth Classes on Pregnant Women Nutritional Behavior. The Scientific Journal of Zanjan University of Medical Sciences. 2013; 21(84): 102-10.

25) Murrin C, Fallon UB, Hannon F, Nolan G, O'Mahony D, Crowley D. Dietary habits of pregnant women in Ireland. Ir Med J. 2007; 100(8): 12-5. PMID: 17955694.

26) Wakita Asano A, Miyoshi M, Arai Y, Yoshita K, Yamamoto S, Yoshiike N. Association between vegetable intake and dietary quality in Japanese adults: a secondary analysis from the National Health and Nutrition Survey, 2003. J Nutr Sci Vitaminol (Tokyo). 2008; 54(5): 384-91. doi: 10.3177/jnsv.54.384. PMID: 19001770.

27) Beck NC, Siegel LJ. Preparation for childbirth and contemporary research on pain, anxiety, and stress reduction: Areview and critique. Psychosom Med. 1980; 42(4): 429-47. doi: 10.1097/00006842198007000-00005. PMID: 7443939.

28) Sturrok WA, Johnson JA. The relationnship between childbirth education classes and obstetric outcome. Birth. 1990; 17(2): 82-5. doi: 10.1111/j.1523-536X.1990.tb00704.x. PMID: 2363770. 